\title{
CEPHALIC VEIN LOOP TRANSPOSITION WITH PROXIMAL RADIAL ARTERY ANASTOMOSES FOR HAEMODIALYSIS
}

\author{
ANDREI ZENOVIA ${ }^{1}$, ANA FULGA ${ }^{2}$, DORIANA CRISTEA ENE ${ }^{3}$, CONSTANTIN STAN $^{4}$, \\ DOINA VESA ${ }^{5}$
}

${ }^{1}$ General CF Hospital Galați, ${ }^{1,2,3,4,5}$ Sf. Andrei Emergency Clinical Hospital of Galați, Dunărea de Jos University Galați

\begin{abstract}
Keywords: transposed cephalic vein, arteriovenous fistula, vascular access, radial artery occlusion

Abstract: In Romania the prevalence of chronic kidney disease is estimated to be $7 \%$ and end-stage renal disease is an increasingly common diagnosis. A long-term, reliable, dependable, and safe method of repeatedly accessing patient's blood is one of the most difficult challenges for haemodialysis therapy. The best method to date to accomplish vascular access the arterio-venous fistula (AVF). This segment can be accessed with dialysis needles, providing blood for dialysis. We present a case of a 57-year-old man was diagnosed with an end-stage renal disease and occluded distal radial artery. The cephalic vein was transposed and looped in a tunnel created in the volar aspect of the forearm's subcutaneous tissue with the end to side anastomosis with the proximal radial artery in the antecubital fossa. The fistula matured in 40 days and the flow volume was $1100 \mathrm{~mL} / \mathrm{min}$. He continues his dialysis sessions and is included on the national kidney transplant list.
\end{abstract}

\section{INTRODUCTION}

As the population ages and the incidence of diabetes rises, chronic kidney disease and end-stage renal disease are increasingly common diagnoses in the Europe. In Romania, the prevalence of chronic kidney disease is estimated to be $7 \%$.(1) There is no doubt that haemodialysis can sustain life in patients who have no kidney function, its primary goal is the replacement of renal excretory function.(2) Survival for as long as 30 years has been documented for haemodialysis alone, a treatment that does nothing more for the patient than remove solute.(3) One of the most difficult challenges for haemodialysis therapy has been, and continues to be, a long-term, reliable, reliable, and safe method of repeatedly accessing the blood of patients. Current methods of access can be split into permanent and temporary access solutions.(4) Preparation for a permanent access, preferably an arterio-venous fistula (AVF), must begin as soon the patient is diagnosed with progressive chronic kidney disease. The preparation initially includes preserving peripheral veins as a future site. The significance of this cannot be sufficiently emphasized, because it is literally the patient's lifeline.(5) For this reason, venepuncture should only use most distal small veins or, if larger veins have to be used, a very experienced person should use these to prevent permanent damage or clotting. In the mid-1960s, Doctors Cimino and Brescia described the AVF, created by subcutaneous anastomosis of the cephalic vein and radial artery. The venous segment arterializes over time, receiving a large flow of arterial blood under pressure, dilates, and develops a thickened wall. This segment can be accessed with dialysis needles, providing blood for dialysis. To date, the AVF is by far the best method of vascular access.(6)

\section{CASE REPORT}

The patient in this case report aged 57-year-old was diagnosed with an end-stage renal disease due to hypertension for which he started haemodialysis in January 2020 and he was sent to the hospital where the dialysis was initiated as an emergency with a temporal catheter. He was addressed to us for a permanent vascular access in April 2020 (three months after initiation of dialysis). On physical examination, his radial pulse was not palpable and had no Doppler signal on the radial artery which occluded but did reconstitute proximally and had a good calibre. He had strong ulnar and palmar arch Doppler signals, and we found a good patent cephalic vein. We considered radial artery reconstruction, but the distal reconstitution was in the palm, and we were not certain that the palmar arch was complete. The decision was made to gain vascular access in his right non-dominant hand in such a way as to preserve his arm arterial vascularization. The proximal radial artery-cephalic vein transposed forearm loop fistula procedure was chosen. The procedure was made using under regional upper arm nerve block anaesthesia. The cephalic vein was carefully dissected from the wrist region to the elbow, using four separate longitudinal skin incisions (figure no.1).

Figure no. 1. Cephalic vein dissection and distension

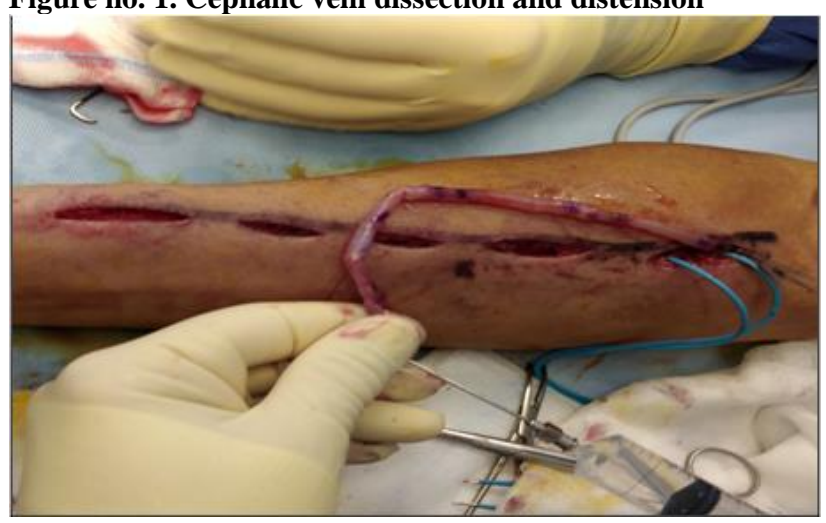

Tributaries were ligated with clips and the vein divided distally for its transposition. Perfusion with heparinized

${ }^{1}$ Corresponding author: Andrei Zenovia, Str. Alexandru Moruzzi Nr. 6, Galați, România, E-mail: zenovia.andrei@gmail.com, Phone: +40747 669866 Article received on 08.02.2021 and accepted for publication on 31.05.2021 


\section{CLINICAL ASPECTS}

saline was routinely performed to confirm its patency, dilate the vein and prevent thrombosis. The proximal part of radial artery was exposed through an incision in the antecubital fossa. A looped tunnel was created in the volar aspect of the forearm's subcutaneous tissue and carefully mobilized to ensure that the vein is not twisted or kinked after passing through (figure no.2).

\section{Figure no. 2. Forearm cephalic vein loop tunneling}

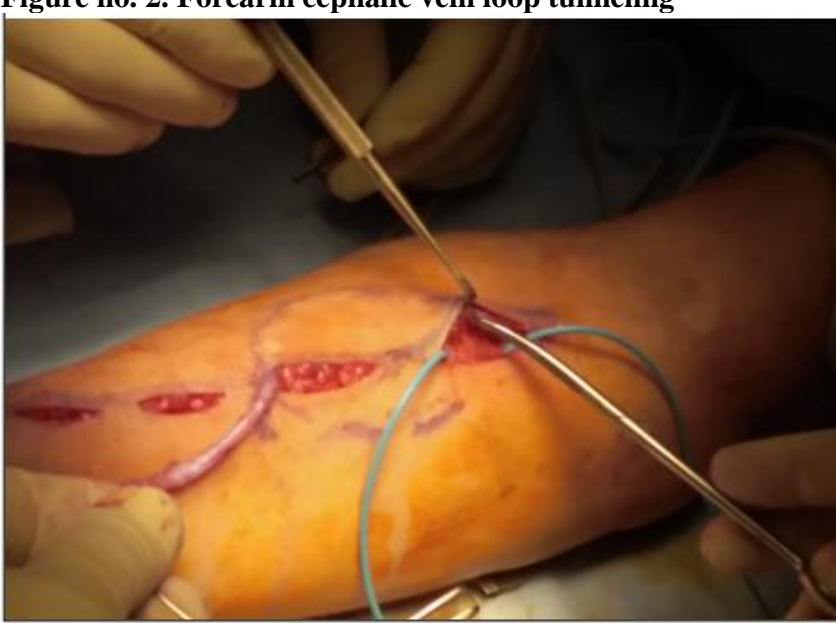

The end-to-side anastomosis with the proximal radial artery was performed using continuous 7-0 polypropylene suture (figures no. 3,4).

Figure no. 3. End-to-side cephalic vein proximal radial artery continuous anastomosis

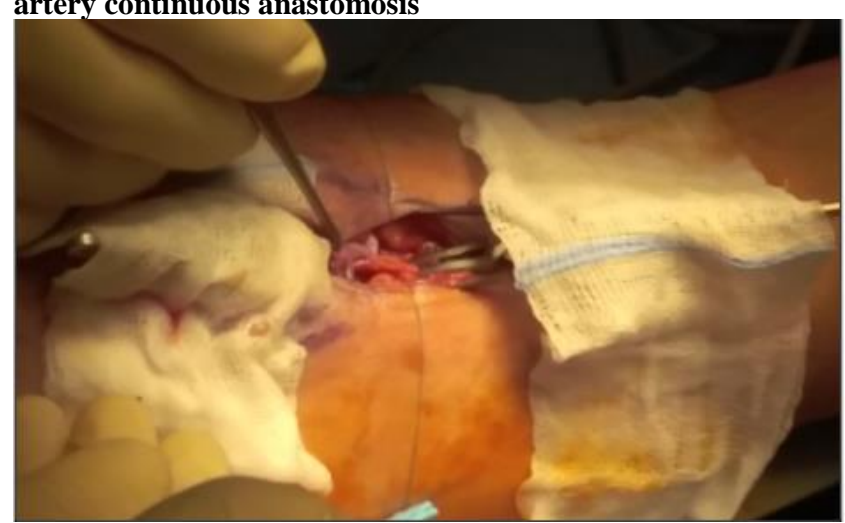

Figure no. 4. Complete cephalic-proximal radial end-to-side anastomosis

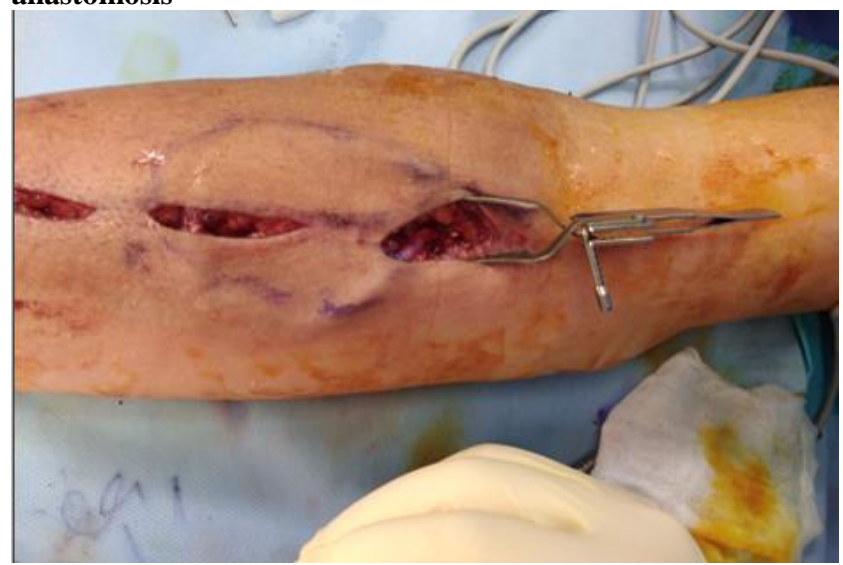

After the confirmation of proper fistula function and precise haemostasis, skin incisions were closed in two layers with one single drain tube left overnight (figure no. 5).
Figure no. 5. Closed incisions and overnight drain placement

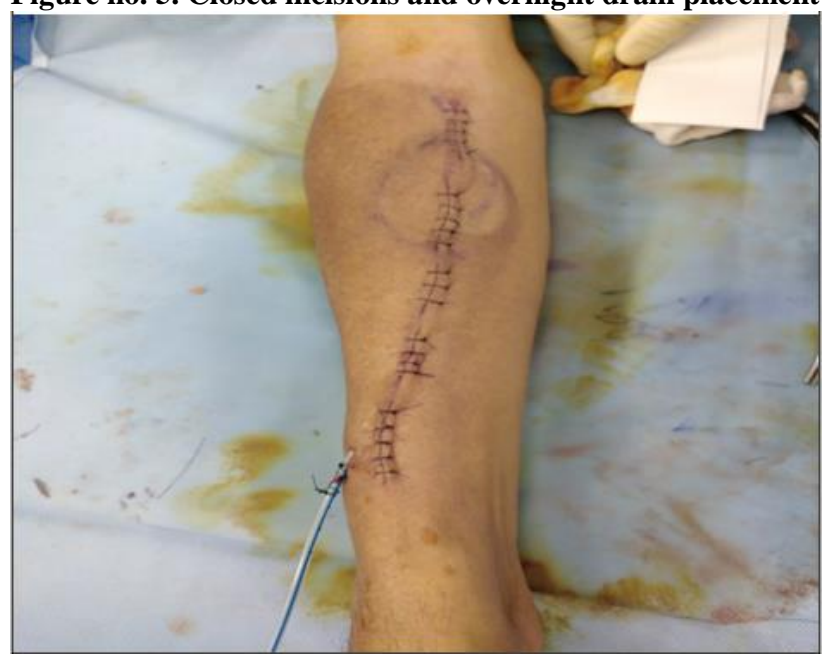

DISCUSSIONS

A major advance in the management of end-stage chronic renal failure has been vascular access for maintenance haemodialysis.(7) Brescia and Cimino, who did a radio-cephalic $\mathrm{AVF}$ at the distal forearm for maintenance dialysis, had the first such access since 1966. Several types of AVF have been described since that time and it is agreed that hierarchically it remains the "workhorse" for the creation of AVF.(8) The choice of a type of vascular access is influence by many factors, the pulse quality through Doppler assessment or direct feel on site, the spontaneous occlusion of the radial artery, or the small size of the vessels such is the case with children.(9) We could have done a trial on the distal right forearm but we believe, since the distal radial artery was occluded, it would not have been successful, while the ulnar artery was instrumental for the limb perfusion. To be considered functional for haemodialysis, the vein must mature, which means it must be at least $6 \mathrm{~mm}$ in diameter and have a flow rate greater than $600 \mathrm{~mL} / \mathrm{min}$, as well as a depth of $6 \mathrm{~mm}$ from the skin for ease of canulation.(10) The maturation time for our patient was about 40 days and the flow were $1100 \mathrm{~mL} / \mathrm{min}$. In addition, it is also possible that, parallel to the arterial site, the course of the looped venous branch in its initial segment (close to the anastomosis) provides better hemodynamicity and thus improves maturation compared to traditional AVF. A number of pharmacological adjuncts are available in order to avoid graft thrombosis like Heparin 4000$10000 \mathrm{U} / \mathrm{L}$ or vein contraction Papaverine $120 \mathrm{mg} / \mathrm{L}$, Glyceryl trinitrate $8.3 \mathrm{mg} / \mathrm{L}$ or Verapamil $16.7 \mathrm{mg} / \mathrm{L}$. For distension of the graft the maximum pressure should not exceed 100-150 mmHg.(11) One relative disadvantage of this technique is represented by the more difficult salvage of the cephalic vein in case of thrombosis.

\section{CONCLUSIONS}

The transposed vein forearm loop AVF receives its inflow at the antecubital fossa bypassing the diseased distal vessels and makes use of the forearm veins. Reliable, long term haemodialysis access can thus be established, while preserving the vasculature of the upper arm for future use. In our case the patient has well tolerated the procedure, and no serious perioperative complications were observed.

He continues his dialysis sessions and is included in the national kidney transplant list. The surgeon must overcome the difficulties of surgery mainly with a precise atraumatic technique of dissection, ligation of tributaries away from the wall, and minimization of time from vein excision to implantation. 


\section{REFERENCES}

1. Cepoi V. The prevalence of chronic kidney disease in the general population in Romania: a study on 60,000 persons, Int Urol Nephrol. 2012;44:2130-220.

2. Pereira BJ. Chronic Kidney Disease, Dialysis, and Transplantation, 2nd ed., Philadelphia: Elsevier; 2005.

3. Lundin AP. Prolonged survival on hemodialysis, In Maher JF(ed): Replacement of Renal Function by Dialysis. 1989; p. 1133-1140.

4. Besarab A. Vascular Access for Hemodialysis, Clinical Nephrology, Dialysis and Transplantation, p. IL.2; 2000.

5. Nissenson AR. Handbook of Dialysis Therapy, 4th ED, Philadelphia: Elsevier; 2008.

6. Ahmad S. Manual of Clinical Dialysis, Washington, USA: Springer; 2009.

7. Williams G. Vascular access. In: Castro J.E. (eds) The Treatment of Renal Failure., Dordrecht: Springer; 1982.

8. Shapira C. Antecubital arteriovenous fistulas with reverse flow, Access Surgery; 1983. p. 313-317.

9. Shenoy S. Surgical anatomy of upper arm: what is needed for AVF planning, J Vasc Access. 2009;10:223-232.

10. Sidaway AN. Recommended standards for reports dealing with arteriovenous hemodialysis access, J Vasc Surg. 2002;335:603-610.

11. Sidawy AN. Autogenous Grafts, in Rutherford's vascular surgery and endovascular therapy, Elsevier; 2019; p. 802. 